\title{
Efektivitas Pembelajaran Berbasis Masalah terhadap Pemahaman Konsep Usaha dan Energi
}

\author{
Luis Varela $^{1}$, Lia Yuliati ${ }^{1}$, Arif Hidayat ${ }^{1}$ \\ ${ }^{1}$ Pendidikan Fisika-Universitas Negeri Malang
}

\begin{tabular}{l}
\hline \hline INFO ARTIKEL \\
\hline Riwayat Artikel: \\
Diterima: 02-05-2019 \\
Disetujui: 24-05-2019 \\
\hline
\end{tabular}

\section{Kata kunci:}

problem-based learning; conceptual understanding; work and energy; pembelajaran berbasis masalah; pemahaman konsep; usaha dan energi

\begin{abstract}
ABSTRAK
Abstract: This study aims to look at the effect of problem-based learning of students' conceptual understanding in work and energy. This study used a quasi-experimental design. The sample used consisted of two classes, namely the experimental class and the control class. The sample selected using cluster random sampling technique. The data obtained through pretest and posttest, then were analyzed using three indicators of conceptual understanding consisting of translation, interpretation, and extrapolation. This study found an increase of conceptual understanding in experimental class better than control class. Although there are had increase, but the increase had not significant.

Abstrak: Penelitian ini bertujuan untuk melihat pengaruh pembelajaran berbasis masalah terhadap pemahaman konsep siswa pada materi usaha dan energi. Penelitian ini menggunakan desain quasi-eksperimen. Sampel yang digunakan terdiri dari dua kelas yang terdiri dari kelas eksperimen dan kelas kontrol. Sampel dipilih menggunakan teknik cluster random sampling. Data diperoleh melalui pretest dan postest, selanjutnya dianalisis menggunakan tiga indikator pemahaman konsep yang terdiri dari translation, interpretation, dan extrapolation. Penelitian ini menemukan terjadi peningkatan pemaham konsep pada kelas eksperimen lebih baik daripada kelas kontrol. Walaupun telah terjadi peningkatan, namun peningakatan yang terjadi belum signifikan.
\end{abstract}

\author{
Alamat Korespondensi: \\ Luis Varela \\ Pendidikan Fisika \\ Universitas Negeri Malang \\ Jalan Semarang 5 Malang \\ E-mail: luisvarelalinu@gmail.com
}

Usaha dan energi merupakan bagian dari materi fisika yang kompleks. Hal ini dikarenakan konsep-konsep di dalamnya saling berkaitan (Robertson et al., 2017; Sabo et al., 2016; Serway \& Jewet, 2014). Materi usaha energi merupakan kajian mekanika klasik yang mempelajari gerak benda dan penyebab benda bergerak (Rahmatina et al., 2018). Materi usaha dan energi merupakan salah satu alternatif konsep yang dapat digunakan dalam menyelesaikan permasalahan gerak benda (Adu-Gyamfi, 2014). Seringkali ditemukan kesulitan siswa dalam memahami konsep usaha dan energi. Kesulitan yang dialami siswa dikarenakan mereka terbiasa memecahkan permasalahan secara matematis (Nikat et al., 2018) dan memecahkan permasalahan terkait usaha dan energi secara intuitif (Chittasirinuwat et al., 2010).

Berdasarkan penelitian terdahulu, ditemukan bahwa siswa kesulitan dalam memahami konsep energi, perubahan energi (Didiş et al., 2014; Sabo et al., 2016), momentum (Dalaklioğlu et al., 2015) dan usaha (Barniol \& Zavala, 2014; Lancor, 2014; Neumann et al., 2013). Selain itu, siswa juga tidak dapat memahami konsep energi potensial dengan baik (Lindsey, 2014) dan salah menentukan grafik hubungan antara energi dengan ketinggian benda (Rahmatina et al., 2018). Kesulitan siswa disebabkan karena tidak utuhnya pemahaman yang mereka miliki (Dalaklioğlu et al., 2015). Peneliti lain juga menunjukkan bahwa konservasi energi mekanik merupakan sub materi usaha dan energi yang paling sulit dipahami (Herrmann-abell \& Deboer, 2011; Lee \& Liu, 2010). Apabila permasalahan ini terus terjadi, siswa akan terus mengalami kesulitan dalam belajar. Kesulitan siswa dapat diatasi dengan memperbaiki pemahaman konsep yang dimiliki oleh siswa. Pemahaman konsep merupakan hal utama yang harus dimiliki oleh siswa dalam proses pembelajaran. Kekeliruan dalam memahami sebuah konsep merupakan suatu hal yang sulit untuk diperbaiki (Berek et al., 2016; Taqwa et al., 2019).

Pemahaman konsep usaha dan energi merupakan kemampuan siswa untuk memahami situasi, membangun makna, dan menciptakan solusi dari permasalahan yang berkaitan dengan konsep usaha dan energi (Buteler \& Coleoni, 2016; Docktor \& Mestre, 2014; Sabo et al., 2016; Taibu et al., 2017). Pemahaman konsep usaha dan energi yang akan dikaji terdiri dari tiga aspek dasar yakni translation (kemampuan menerjemahkan), interpretation (kemampuan menafsirkan), dan extrapolation (kemampuan memperhitungkan) (Bloom et al., 1971). Siswa yang memiliki pemahaman konsep yang baik pada materi usaha dan energi diyakini mampu menerjemahkan kompleksitas, menafsirkan fenomena yang terkait, dan memperhitungkan konsep yang akan digunakan untuk membangun pemahaman yang utuh terkait materi usaha dan energi (Barniol \& Zavala, 2014; Sabo et al., 2016). 
Usaha untuk meningkatkan pemahaman konsep siswa dapat dilakukan melaui berbagai cara, salah satunya dengan menerapkan pembelajaran yang memberikan kesempatan siswa mendapatkan pengetahuan secara mandiri. Pemahaman konsep materi usaha dan energi memerlukan sebuah model pembelajaran yang berorientasi pada permasalahan khusus (Barniol \& Zavala, 2014; Docktor et al., 2015; Sabo et al., 2016) dan berbasis konstruktivistik (Docktor \& Mestre, 2014). Salah satu pembelajaran yang dapat diterapkan adalah pembelajaran berbasis masalah. Pembelajaran berbasis masalah merupakan model pembelajaran yang melibatkan siswa dalam sebuah masalah nyata (Arends, 2012; Loyens et al., 2015; Wirkala \& Kuhn, 2011). Masalah yang diberikan berfungsi sebagai rangsangan agar siswa mempelajari konsep fisika (Davidson \& Major, 2014), sehingga akan berdampak ketika siswa menyelesaikan permasalahan dalam kehidupan sehari-hari (Raine \& Symons, 2012).

Pembelajaran berbasis masalah diorganisasikan di sekitar situasi kehidupan nyata yang menghindari jawaban sederhana dan mengundang berbagai pemecahan yang berkaitan. Karakteristik utama pada pembelajaran berbasis masalah meliputi pengajuan pertanyaan atau masalah, pemusatan antar disiplin, penyelidikan autentik, kerja sama serta menghasilkan karya (Arends, 2012). Pembelajaran berbasis masalah akan menimbulkan perubahan pemahaman konsep siswa ke arah positif baik dalam ranah kognitif, afektif, dan psikomotor sesuai dengan tujuan pembelajaran yang telah ditentukan.

Dekade terakhir, pembelajaran berbasis masalah telah digiatkan dalam upaya memperbaiki pemahaman konsep siswa. Namun, penerapan pembelajaran berbasis masalah di Timor Leste masih jarang dilakukan. Hal ini terlihat dari sedikitnya karya ilmiah yang terpublikasikan terkait pembelajaran berbasis masalah di Timor Leste. Pembelajaran di Timor Leste cenderung berpusat kepada guru (da Cruz et al., 2017; Goncalves \& Savio, 2017) dan kurang memanfaatkan kegiatan laboratorium (Moreira \& Filomeno, 2017), sehingga siswa kurang diberikan kesempatan dalam membangun pemahamannya sendiri. Penerapan pembelajaran berbasis masalah yang bertujuan untuk membangun pemahaman konsep siswa perlu dilakukan sebagai salah satu urgensi inovasi pembelajaran di Timor Leste. Melalui penerapan pembelajaran berbasis masalah diharapkan siswa memiliki pemahaman konsep yang baik dan utuh.

\section{METODE}

Penelitian ini dilakukan pada siswa kelas X Eksakta di SMA Katolik Sao Pedro di Timor Leste. Penelitian ini menggunakan pendekatan kuantitatif dengan desain quasi-eksperimen, desain yang digunakan disajikan pada tabel 1.

Tabel 1. Desain Penelitian Quasi-Eksperimen

\begin{tabular}{lccc}
\hline \multicolumn{1}{c}{ Kelas } & Pretest & Perlakuan & Posttest \\
\hline Kontrol & $\mathrm{X}_{1}$ & $\mathrm{O}$ & $\mathrm{X}_{2}$ \\
\hline Eksperimen & $\mathrm{X}_{1}$ & $\mathrm{O}$ & $\mathrm{X}_{2}$ \\
\hline
\end{tabular}

\section{Sumber: Creswell (2012)}

Pengambilan data pada tahapan pre-test $\left(\mathrm{X}_{1}\right)$ pada kelas kontrol dan kelas eksperimen dilakukan menggunakan instrumen tes pemahaman konsep. Setelah pengambilan data pre-test, selanjutnya dilakukan pembelajaran (O). Pembelajaran kelas kontrol menggunakan pembelajaran konvensional, sedangkan kelas eksperimen menggunakan pembelajaran berbasis masalah.

Sampel yang digunakan pada penelitian ini terdiri dua kelas yang diambil menggunakan teknik cluster sampling. Kelas pertama yakni siswa kelas X Eksakta 1 sebagai eksperimen yang belajar dengan pembelajaran berbasis masalah, sedangkan kelas kedua siswa kelas X Eksakta 2 sebagai kelas kontrol yang belajar dengan pembelajaran konvensional. Langkah-langkah pembelajaran pada masing-masing kelas disajikan pada tabel 2.

Tabel 2. Langkah-langkah Pembelajaran pada Masing-masing Kelas

\begin{tabular}{cll}
\hline Langkah & \multicolumn{1}{c}{ Kelas Kontrol } & \multicolumn{1}{c}{ Kelas Eksperimen } \\
\hline 1 & Menjelaskan tujuan pembelajaran & Berpusat pada masalah \\
\hline 2 & Mendemonstrasikan pengetahuan & Mengorganisasikan siswa untuk belajar \\
\hline 3 & Memberikan praktik terpadu & Membimbing penyelidikan individu dan kelompok \\
\hline 4 & Memeriksa pemahaman siswa dan umpan balik & Mengembangkan dan menyajikan hasil karya \\
\hline 5 & Menyediakan latihan mandiri & Menganalisa dan mengevaluasi pemecahan masalah \\
\hline
\end{tabular}

Berdasarkan tabel 2, pembelajaran pada kelas kontrol cenderung berfokus kepada guru, sedangkan pada kelas eksperimen lebih difokuskan kepada siswa sendiri dalam mendapatkan pengetahuannya. Melalui cara ini, diharapkan siswa dapat memahami materi yang diajarkan lebih mendalam dan bermakna. Setelah pembelajaran selesai, selanjutnya dilakukan pengambilan data post-test $\left(\mathrm{X}_{2}\right)$. Skor jawaban siswa yang diperoleh saat pretest dan posttest dianalisis untuk mengetahui peningkatan pemahaman siswa terkait materi usaha dan energi. Analisis yang digunakan meliputi uji beda dan uji $d$-effect size. 


\section{HASIL}

Data pre-test dan post-test dianalisis dengan uji statistik daya beda menggunakan Mann-Whitney Test untuk mengetahui perbedaan pemahaman konsep materi usaha dan energi antara siswa kelas X Eksakta di SMA Katolik Sao Pedro yang belajar dengan pembelajaran berbasis masalah dan pembelajaran konvensional. Hasil uji statistik daya beda Mann-Whitney Test disajikan pada tabel 3.

Tabel 3. Hasil Uji Mann-Whitney Test Pemahaman Konsep Siswa

\begin{tabular}{lcc}
\hline \multirow{2}{*}{ Statistik } & \multicolumn{2}{c}{ Nilai } \\
\cline { 2 - 3 } & Pretest & Posttest \\
\hline Mann-Whitney $U$ & 683,000 & 706,000 \\
\hline Wilcoxon $W$ & 1908,000 & 1931,000 \\
\hline$Z$ & $-3,836$ & $-3,621$ \\
\hline Asymp.Sig.(2-tailed) & 0,000 & 0,000 \\
\hline
\end{tabular}

Berdasarkan tabel 3, terlihat bahwa terdapat perbedaan pemahaman konsep materi usaha dan energi pada siswa kelas eksperimen dan kelas kontrol. Perbedaan ini terlihat dari perolehan nilai Asymp.Sig.(2-tailed) sebesar 0,000 pada skor pre-test dan post-test. Setelah diketahui adanya perbedaan pemahaman konsep siswa, selanjutnya dilakukan uji pengaruh pembelajaran berbasis masalah terhadap pemahaman konsep siswa. Analisis pengaruh pembelajaran berbasis masalah terhadap pemahaman konsep siswa dianalisis menggunakan uji $d$-effect size. Hasil analisis $d$-effect size disajikan pada tabel 4.

Tabel 4. Hasil Analisis d-Effect Size Pemahaman Konsep

\begin{tabular}{ccc}
\hline Kelas & Nilai $\boldsymbol{d}$-Effect Size & Kriteria \\
\hline Eksperimen & 0,8 & Tinggi \\
Kontrol & 0,7 & Sedang \\
\hline
\end{tabular}

Berdasarkan tabel 4, terlihat bahwa nilai $d$-effect size, pada kelas eksperimen memiliki efek peningkatan pada kriteria tinggi dengan skor 0,8, sedangkan pada kelas kontrol memiliki efek peningkatan pada kriteria sedang dengan skor 0,7.

\section{PEMBAHASAN}

Pemahaman konsep siswa pada materi usaha dan energi setelah belajar dengan pembelajaran berbasis masalah dianalisis melalui skor pre-test dan post-test. Siswa diberikan soal pemahaman konsep materi usaha dan energi. Hasil penelitian menunjukkan bahwa terdapat perbedaan pemahaman konsep siswa pada materi usaha dan energi yang belajar dengan pembelajaran berbasis masalah dibandingkan dengan yang belajar dengan pembelajaran konvensional. Hal ini terlihat pada signifikansi pada skor pretest sebesar 0,000 dan signifikasi pada skor posttest sebesar 0,000. Peningkatan tersebut juga dapat dilihat dari perbedaan jawaban siswa pada kelas eksperimen dan kelas kontrol. Soal yang digunakan disajikan pada gambar 1.

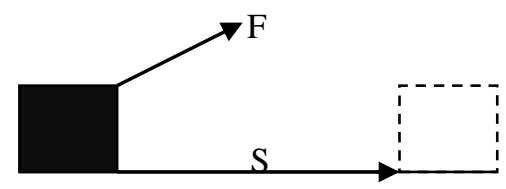

\section{Gambar 1. Soal Pemahaman Konsep Siswa}

Soal pada gambar 1 merupakan soal konsep usaha, siswa diminta menerapkan konsep usaha untuk menghitung besarnya usaha yang dilakukan balok untuk bergerak. Jawaban siswa pada kelas eksperimen dan kelas kontrol disajikan pada tabel 5. Berdasarkan tabel 5, terlihat bahwa siswa pada kelas eksperimen telah mampu menyelesaikan permasalahan yang diberikan menggunakan konsep yang benar. Selain itu, siswa juga menggunakan indikator pemahaman konsep yang berupa translation, interpretation, dan extrapolation (Bloom et al., 1971). Hal ini menunjukkan bahwa siswa mampu menerjemahkan kompleksitas konsep usaha yang diberikan. Hal berbeda ditunjukkan pada kelas kontrol, siswa pada kelas kontrol mengerjakan soal yang diberikan hanya menggunakan perhitungan matematis seperti yang ditunjukkan pada tabel 4. Sehingga tidak dapat menentukan konsep apa yang digunakan sebelum melakukan perhitungan.

Ketika siswa hanya mampu menerapkan persamaan matematis, hal ini menunjukkan bahwa siswa masih memiliki pemahaman konsep yang rendah (Docktor \& Mestre, 2014; Nikat et al., 2018) dan kurang memahami makna sebenarnya dari permasalahan yang diberikan (Priyadi et al., 2018). Selain itu, terlihat juga bahwa pada kelas kontrol siswa masih mengalami kesulitan dalam memahami simbol-simbol pada konsep usaha. Siswa pada kelas kontrol menuliskan usaha sebagai m dan jarak sebagai f. Berdasarkan uraian tersebut, terlihat bahwa terdapat perbedaan pemahaman konsep antara siswa kelas eksperimen yang belajar dengan pembelajaran berbasis masalah dan kelas kontrol yang belajar dengan pembelajaran konvensional. 
Ketika siswa hanya mampu menerapkan persamaan matematis, hal ini menunjukkan bahwa siswa masih memiliki pemahaman konsep yang rendah (Docktor \& Mestre, 2014; Nikat et al., 2018) dan kurang memahami makna sebenarnya dari permasalahan yang diberikan (Priyadi et al., 2018). Selain itu, terlihat juga bahwa pada kelas kontrol siswa masih mengalami kesulitan dalam memahami simbol-simbol pada konsep usaha. Siswa pada kelas kontrol menuliskan usaha sebagai m dan jarak sebagai f. Berdasarkan uraian tersebut, terlihat bahwa terdapat perbedaan pemahaman konsep antara siswa kelas eksperimen yang belajar dengan pembelajaran berbasis masalah dan kelas kontrol yang belajar dengan pembelajaran konvensional.

Perbedaan peningkatan pemahaman konsep siswa setelah belajar dengan pembelajaran berbasis masalah dan belajar dengan pembelajaran konvensional terlihat pada nilai d-effect size. Kelas eksperimen memiliki efek peningkatan pada kriteria tinggi $(\mathrm{d}=0,8)$, sedangkan pada kelas kontrol memiliki efek peningkatan pada kriteria sedang $(\mathrm{d}=0,7)$. Hasil analisis menunjukkan bahwa terdapat pengaruh pembelajaran berbasis masalah terhadap pemahaman konsep siswa pada materi usaha dan energi. Pengaruh pembelajaran berbasis masalah terhadap pemahaman konsep siswa dilihat dari nilai pretest dan posttest siswa pada pemahaman konsep materi usaha dan energi. Hal serupa juga ditunjukkan oleh peneliti lainnya, bahwa penerapan pembelajaran berbasis masalah dapat meningkatkan (Dwi et al., 2013; Gijbels et al., 2005) dan mengubah pemahaman konsep siswa (Hung et al., 2007; Loyens et al., 2015).

Berdasarkan skor yang diperoleh, walaupun terdapat perbedaan peningkatan pemahaman konsep antara siswa yang belajar dengan pembelajaran berbasis masalah dengan siswa yang belajar dengan pembelajaran konvensional. Namun, perbedaan peningkatan yang terjadi tidak terlalu tinggi. Hal ini disebabkan oleh beberapa faktor penghambat dalam proses pembelajaran. Faktor tersebut adalah sumber belajar yang tidak dimiliki siswa dan tidak tersedianya fasilitas pembelajaran yang menunjang proses pembelajaran. Proses pembelajaran yang belum maksimal untuk meningkatkan pemahaman konsep siswa menjadi faktor penting dalam pemahaman konsep siswa yang berimplikasi terhadap capaian hasil belajar siswa (Hung, 2016; Strobel \& van Barneveld, 2009).

Tabel 5. Jawaban Siswa pada Kelas Eksperimen dan Kelas Kontrol

\begin{tabular}{|c|c|}
\hline Kelas & Jawaban Siswa \\
\hline Eksperimen & 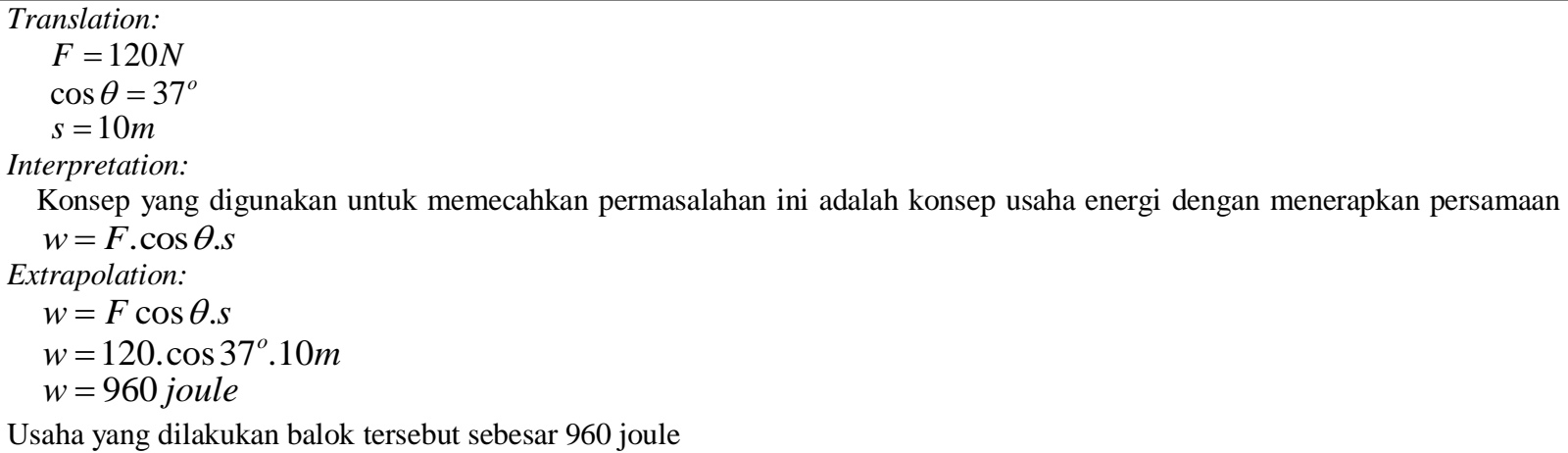 \\
\hline Kontrol & $\begin{array}{ll}\text { Translation: } & \text { Extrapolation: } \\
f=120 m & m=f \cdot d \cdot \cos \theta \\
\theta=37^{\circ} & m=120 \cdot 10 \cdot \cos \left(37^{\circ}\right) \\
f=10 m & m=1200 \cdot \sqrt{3 / 2} \\
m=\ldots \ldots . ? & m=\frac{1200 \cdot \sqrt{3}}{2} \\
& m=600 \sqrt{3 / 2}\end{array}$ \\
\hline
\end{tabular}

\section{SIMPULAN}

Peningkatan pemahaman konsep siswa mealui pembelajaran berbasis masalah lebih tinggi dari pada melalui pembelajaran konvensional. Peningkatan ini terjadi dikarenakan langkah-langkah pada pembelajaran berbasis masalah dapat melatih dan meningkatkan kognitif siswa dengan mendapatkan sendiri konsep-konsep yang diajarkan. Sehingga siswa tidak hanya mendapat ilmu dari guru, tetapi membangun sendiri pemahamannya melalui diskusi dan kegiatan eksperimen. Perhatian para pendidik dan peneliti lainnya untuk lebih fokus dalam meningkatkan pemahaman konsep siswa agar mereka tidak mengalami kendala dalam mempelajari konsep usaha dan energi. Serta diperlukan penelitian-penelitian lebih lanjut terkait penerapan pembelajaran yang lebih tepat untuk meningkatkan pemahaman konsep siswa. Selain itu, diperlukan juga kajian lebih dalam terkait pengaruh pembelajaran berbasis masalah di Timor Leste agar tercipta sumber daya manusia yang unggul dan dapat bersaing secara global. 


\section{DAFTAR RUJUKAN}

Adu-Gyamfi, K. (2014). Using the Activity Method to Enhance Students' Performance in Energy Transformation. International Journal of Research Studies in Educational Technology, 3(1), 87-97. DOI:10.5861/ijrset.2014.594

Arends, R. I. (2012). Learning to Teach (9th ed.). New York: The McGraw-Hill Companies, Inc.

Barniol, P., \& Zavala, G. (2014). Force, Velocity, and Work: The Effects of Different Contexts on Students' Understanding of Vector Concepts using Isomorphic Problems. Physical Review Special Topics - Physics Education Research, 10(2), 020115. DOI:10.1103/PhysRevSTPER.10.020115

Berek, F. X., Sutopo, \& Munzil, M. (2016). Concept Enhancement of Junior High School Students in Hydrostatic Pressure and Archimedes Law by Predict-Observe-Explain Strategy. Jurnal Pendidikan IPA Indonesia, 5(2), 230-238. DOI:10.15294/jpii.v5i2.6038

Bloom, B. S., Hastings, T., \& Madaus, G. F. (1971). Handbook on Formative and Summative Evaluation of Student Learning. New York: McGraw-Hill.

Buteler, L., \& Coleoni, E. (2016). Solving Problems to Learn Concepts, How Does it Happen? A Case for Buoyancy. Physical Review Physics Education Research, 12(2), 020144. DOI:10.1103/PhysRevPhysEducRes.12.020144

Chittasirinuwat, O., Kruatong, T., \& Paosawatyanyong, B. (2010). College Students' Intuitive Understanding and ProblemSolving of Energy and Momentum. AIP Conference Proceedings, 1263(1), 79-82. DOI:10.1063/1.3479899

Creswell, J. W. (2012). Educational Research: Planning, Conducting, and Evaluating Quantitative and Qualitative Research (4th ed.). Boston, MA: Pearson Education, Inc.

da Cruz, R., de Jesus, A. A., \& Soares, G. (2017). Teacher's Role in Learning Management to Improve Biology Learning Achievement. Journal of Innovative Studies on Character and Education, 1(1), 145-163.

Dalaklioğlu, S., Demirci, N., \& Şekercioğlu, A. (2015). Eleventh Grade Students' Difficulties and Misconceptions about Energy and Momentum Concepts. International Journal on New Trends in Education and Their Implications, 6(1), 13-21.

Davidson, N., \& Major, C. H. (2014). Boundary Crossings: Cooperative Learning, Collaborative Learning, and Problem-Based Learning. Journal on Excellence in College Teaching, 25(3\&4), 7-55. http://celt.miamioh.edu/ject/fetch.php?id=592

Didiş, N., Eryılmaz, A., \& Erkoç, Ş. (2014). Investigating Students' Mental Models About the Quantization of Light, Energy, and Angular momentum. Physical Review Special Topics - Physics Education Research, 10(2), 020127. DOI:10.1103/PhysRevSTPER.10.020127

Docktor, J. L., \& Mestre, J. P. (2014). Synthesis of Discipline-based Education Research in Physics. Physical Review Special Topics - Physics Education Research, 10(2), 020119. DOI:10.1103/PhysRevSTPER.10.020119

Docktor, J. L., Strand, N. E., Mestre, J. P., \& Ross, B. H. (2015). Conceptual Problem Solving in High School Physics. Physical Review Special Topics - Physics Education Research, 11(2), 020106. DOI:10.1103/PhysRevSTPER.11.020106

Dwi, I. M., Hidayat, A., \& Kusairi, S. (2013). Pengaruh Strategi Problem Based Learning Berbasis ICT terhadap Pemahaman Konsep dan Kemampuan Pemecahan Masalah Fisika. Jurnal Pendidikan Fisika Indonesia, 9(1), 8-17. http://journal.unnes.ac.id/nju/index.php/JPFI

Gijbels, D., Dochy, F., Van den Bossche, P., \& Segers, M. (2005). Effects of Problem Based Learning: A Meta-Analysis from the Angle of Assessment. Review of Educational Research, 75(1), 27-61.

Goncalves, A. dos S., \& Savio, D. (2017). The Influence of Productivity of the Teacher for the Quality of Learning Teaching. Journal of Innovative Studies on Character and Education, 1(1), 68-87.

Herrmann-abell, C. F., \& Deboer, G. E. (2011). Investigating Students' Understanding of Energy Transformation, Energy Transfer, and Conservation of Energy Using Standards-Based Assessment Items. Narst, 1-13.

Hung, W. (2016). All PBL Starts Here: The Problem. Interdisciplinary Journal of Problem-Based Learning, 10(2). DOI:10.7771/1541-5015.1604

Hung, W., Jonassen, D. H., \& Liu, R. (2007). Problem-Based Learning. In J. M. Spector, J. G. van Merriënboer, M. D. Merril, \& D. Driscoll (Eds.), Handbook of Research on Educational Communications and Technology (3rd ed., pp. 1503-1581). New Jersey: Lawrence Erlbaum Associates.

Lancor, R. A. (2014). Using Student-Generated Analogies to Investigate Conceptions of Energy: A Multidisciplinary Study. International Journal of Science Education, 36(1), 1-23. DOI:10.1080/09500693.2012.714512

Lee, H.-S., \& Liu, O. L. (2010). Assessing Learning Progression of Energy Concepts Across Middle School Grades: The Knowledge Integration Perspective. Science Education, 94(4), 665-688. DOI:10.1002/sce.20382

Lindsey, B. A. (2014). Student Reasoning about Electrostatic and Gravitational Potential Energy: An Exploratory Study with Interdisciplinary Consequences. Physical Review Special Topics - Physics Education Research, 10(1), 013101. DOI:10.1103/PhysRevSTPER.10.013101

Loyens, S. M. M., Jones, S. H., Mikkers, J., \& van Gog, T. (2015). Problem-Based Learning as A Facilitator of Conceptual Change. Learning and Instruction, 38, 34-42. DOI:10.1016/j.learninstruc.2015.03.002

Moreira, I. X., \& Filomeno, C. B. (2017). Effectiveness of the Implementation the Demonstration Method to Increase the Result of Physic Study On Electric Resistance. Journal of Innovative Studies on Character and Education, 1(1), 104-118.

Neumann, K., Viering, T., Boone, W. J., \& Fischer, H. E. (2013). Towards a Learning Progression of Energy. Journal of Research in Science Teaching, 50(2), 162-188. DOI:10.1002/tea.21061 
Nikat, R. F., Parno, \& Latifah, E. (2018). The Evaluation Of Physics Students' Problem-Solving Ability Through Mauve Strategy (Magnitude, Answer, Units, Variables, And Equation). PEOPLE: International Journal of Social Sciences, 3(3), 1234-1251. DOI:10.20319/pijss.2018.33.12341251

Priyadi, R., Mustajab, A., Tatsar, M. Z., \& Kusairi, S. (2018). Analisis Kemampuan Berpikir Kritis Siswa SMA Kelas X MIPA dalam Pembelajaran Fisika. Jurnal Pendidikan Fisika Tadulako, 6(1), 53-55. DOI:10.22487/j25805924.2018.v6.i1.10020

Rahmatina, D. I., Sutopo, \& Wartono. (2018). Identifikasi Kesulitan Siswa SMA pada Materi Usaha-Energi. Momentum: Physics Education Journal, 2(1), 8. DOI:10.21067/mpej.v1i1.2240

Raine, D., \& Symons, S. (2012). Problem-Based Learning: Undergraduate Physics by Research. Contemporary Physics, 53(1), 39-51. DOI:10.1080/00107514.2011.615162

Robertson, A. D., Scherr, R. E., Goodhew, L. M., Daane, A. R., Gray, K. E., \& Aker, L. B. (2017). Identifying Content Knowledge for Teaching Energy: Examples from High School Physics. Physical Review Physics Education Research, 13(1), 010105. DOI:10.1103/PhysRevPhysEducRes.13.010105

Sabo, H. C., Goodhew, L. M., \& Robertson, A. D. (2016). University Student Conceptual Resources for Understanding Energy. Physical Review Physics Education Research, 12(1), 010126. DOI:10.1103/PhysRevPhysEducRes.12.010126

Serway, R. A., \& Jewet, J. W. (2014). Physics for Scientists and Engineers with Modern Physics Ninth Edition. United States: Brooks/Cole Cengage Learning.

Strobel, J., \& van Barneveld, A. (2009). When is PBL More Effective? A Meta-synthesis of Meta-Analyses Comparing PBL to Conventional Classrooms. Interdisciplinary Journal of Problem-Based Learning, 3(1). DOI:10.7771/1541-5015.1046

Taibu, R., Schuster, D., \& Rudge, D. (2017). Teaching Weight to Explicitly Address Language Ambiguities and Conceptual Difficulties. Physical Review Physics Education Research, 13(1), 010130. DOI:10.1103/PhysRevPhysEducRes.13.010130

Taqwa, M. R. A., Priyadi, R., \& Rivaldo, L. (2019). Pemahaman Konsep Suhu dan Kalor Mahasiswa Calon Guru. Jurnal Pendidikan Fisika Universitas Muhammadiyah Metro, 7(1), 56-67.

Wirkala, C., \& Kuhn, D. (2011). Problem-Based Learning in K-13 Education: Is it Effective and How Does it Achieve its Effects? American Educational Research Journal, 48, 1157-1186. DOI:10.3102/0002831211419491 